\title{
Algunas estrategias académicas para el fortalecimiento internacional del español
}

\author{
Guillermo \\ Pulido González y \\ Erika \\ Erdely Ruíz \\ CEPE-UNAM
}

INTRODUCCIÓN

El objetivo principal de este artículo es mostrar el trabajo que ha desarrollado la Universidad Nacional Autónoma de México (UNAM) para la enseñanza y difusión de la lengua y la cultura de México en países no hispanohablantes, principalmente en Estados Unidos, ${ }^{1}$ como propuesta de al gunas estrategias académicas que pueden llevarse a cabo para contribuir a una exitosa difusión de la lengua española en países no hispanohablantes.

Reflexionaremos sobre el estado actual del español en el contexto gl obalizado con que iniciamos este siglo, los cambios demográficos de los últimos años y las tendencias hacia el futuro. Haremos una síntesis del trabajo realizado en la UNAM desdela creación, en 1921, del Centro de Enseñanza para Extranjeros (CEPE) y la creación y desarrollo de sus escuelas en Estados Unidos y Canadá.

Desglosaremos los proyectos estructurales que el CEPE ha venido trabajando con mayor intensidad en los últimos años en cuatro ejes fundamentales:

1. Nuevo plan de estudios de español y cultura mexicana en ocho niveles con serie de libros y exámenes para cada nivel —homologado a los niveles del Marco Común de Referencia Europeo para la enseñanza de lenguas.

2. Certificación de nivel de dominio de la lengua.

3. Formación docente - en vinculación con Universidades de Estados Unidos y Canadá.

4. Programa de Bachillerato a distancia, en español, en Estados Unidos y Canadá.

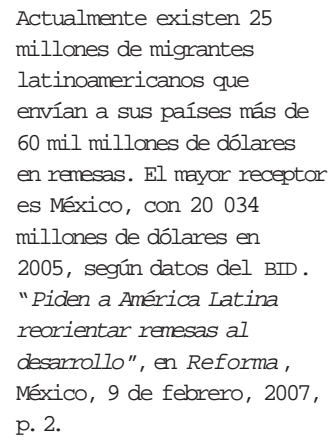


Ramírez Ramírez, Víctor Hugo, Lengua y diplomacia: la promoción lingüística como elemento de política exterior. México, 2006. Tesis, El Colegio de México,p. 18. 3 Ibid., p. 28.
Partiendo de la perspectiva que plantea Ramírez, ${ }^{2}$ quien sostiene que "la promoción exterior de una lengua constituye una estrategia de promoción cultural de un estado-nación en concordancia con los intereses de su política exterior y cuyos alcances se encuentran determinados por el grado poder lingüístico", consideramos que los proyectos que la UNAM ha desarrollado en materia de difusión del español, constituyen al gunas estrategias académicas que pueden llevar a cabo los países hispanohablantes para fortalecer el crecimiento de nuestro idioma y nuestra cultura en el exterior. Estos proyectos, que desglosaremos en el cuerpo de este trabajo, tienen por objeto no sól o el establecimiento de objetivos y contenidos de enseñanza y evaluación de la lengua, sino también la creación de un marco de val idez internacional, al corresponderse con los criterios establecidos por el Marco Europeo Común de Referencia para Ias Lenguas. Cada acción contribuye al fomento del español, pero más importante aún es la interrelación que existe entre cada una de las acciones y su vinculación con la realidad educativa internacional.

En este sentido, consideramos que es de suma importancia que la difusión del español no sólo constituya una prioridad en la política exterior de cada país hispanohablante, sino que también las entidades gubernamentales y las universidades de América Latina unan esfuerzos para impulsar políticas de promoción lingüística en el exterior, impulsando todas las acciones que puedan plantearse y que conlleven a una influencia más real del mundo hispanohablante en español y que las aportaciones del mundo hispano en materia científica, política, económica y cultural puedan darse en español y ser reconocidas internacionalmente.

\section{EL ESPAÑOL EN EL MUNDO}

Según Ramírez, ${ }^{3}$ una forma recurrente de intentar medir el grado de influencia de las lenguas la proveen cuatro criterios que podríamos llamar clásicos: 1) el demolingüístico., 2) el número de hablantes de una lengua; 3) el 
econol ingüístico, es decir, la importancia económica de sus comunidades de habla; 4) el glotopolítico, su uso como lengua oficial o de organizaciones internacionales y el prestigio socio-literario, medido por la publicación de textos. En cada uno de estos criterios y según diversas fuentes oficiales de información citadas por Ramírez, el español aparece entre los primeros tres lugares.

El español es, según el criterio demolingüístico, la tercera lengua del mundo, después del chino (mandarín) y el inglés. ${ }^{4}$ Pese a ser una lengua hablada en zonas distantes, hasta ahora existe una cierta uniformi dad en el nivel culto del idioma que permite a las personas de uno u otro lado del Atlántico e intracontinental mente entenderse con relativa facilidad. Las mayores diferencias son de carácter suprasegmental —es decir, la variada entonación-y lexical, que es uno de los aspectos lingüísticos que con mayor obviedad refleja la variación dial ectal, por razones históricas - principal mente las diferencias en fechas de ll egada de los español es a las distintas zonas de América-y por la influencia de las lenguas autóctonas americanas. ${ }^{5} \mathrm{Sin}$ embargo, la ortografía y la norma lingüística aseguran la uniformidad de la lengua; de ahí la necesidad de colaboración entre las diversas Academias de la Lengua para preservar la unidad, hecho al que contribuye de manera rel evante la difusión de los productos literarios, científicos, pedagógicos, cinematográficos, televisivos, comunicadores e informáticos.

El español es el segundo idioma hablado en Estados Unidos, país que cuenta con varias cadenas de radio y televisión con emisiones totalmente en español; asimismo, y por razones estrictamente económicas, es la lengua que más se estudia como idioma extranjero en los países no hispanohablantes de América y Europa. Según Antonio Aja, del Centro de Estudios de Migraciones Internacional es de la Universidad de la Habana, "25 millones de latinoamericanos viven fuera de sus países de origen, 18 millones de ellos en Estados Unidos, 4 millones en países de propia región y el resto en otras zonas del mundo, principalmente en Europa". ${ }^{6}$

Lejanosyalostiempos en queel español fueconsiderada la lengua diplomática, cuando fue sustituida por el francés, hoy es lengua oficial de la (Organización de las Naciones
4 Por supuesto los datos varían según la fuente y el año de publicación. Fuentes de 1996, como The Atlas of Languages, editado por Bernard Comrie, Stephen Matthews y Maria Polinsky y de 1997, como el volumen 2 de Language Today, de George Weber, colocan al español en ter cer lugar. Sin embargo, una fuente más reciente, de 1999, el Ethnologue Survey del Summer Institute for Linguistics, lo coloca ya arriba del inglés, en segundo lugar después del chino.

Cristina Simón. Curso:

"Variantes Dialectales del

Español", del Diplomado en

Formación de Profesores de Español, [en línea] 〈http:// diplomados. cepe.unam.mx/ DFPELE/index.html> [Consulta: febrero, 2007]. Piden a América Latina reorientar..., q.cit. 
Unidas) y sus organismos, de la Unión Europea y otros organismos internacionales. Hasido incluida como idioma dentro de las grandes autopistas internacional es de la información como I nternet, lo que asegura la constante traducción de lasinnovaciones informáticas, su difusión eintercomunicación.

Así, todo parece augurar, que en el siglo XXI el español será una de las lenguas de mayor difusión. Esimportante, por lo tanto, que quienes tenemos la fortuna de hablarlo, realicemos todos los días la más fuerte defensa de sus principios y su preservación para continuar con el gran legado de hombres como Cervantes Saavedra, Octavio Paz, Nebrija, Borges, Amado Nervo, García Márquez y tantos más que tan bien se han expresado con ella.

\section{ORÍGENES Y DESARROLLO DEL CEPE}

EI CEPE es una institución de la UNAM que, a lo largo de su existencia, ha construido una historia de éxito en los campos de la enseñanza y difusión de la lengua y cultura mexicana.

En el año de su fundación, 1921, el Centro fue concebido como una Escuela de Verano. La idea era que los al umnos del extranjero, principalmente de Estados Unidos, tomaran cursos de español, historia, literatura y arte. En pocas palabras, mostrarles lo mejor de México y transformarlos en embajadores de nuestra lengua y cultura.

El entonces rector, J osé Vasconcel os, fue su fundador y contó con el apoyo de intel ectuales de talla internacional. Hombres que eran una muestra de la mejor inteligencia de la época. Sin duda al guna, figuras como Pedro Henríquez Ureña, J ulio Torri, Vicente Lombardo Toledano, Carlos Pellicer, Alfonso Caso, J ai me Torres Bodet, Daniel Cosío Villegas, Manuel Gómez Morín y Manuel Gamio, entre otros destacados universitarios, tuvieron mucho quever en el futuro y el éxito del proyecto educativo.

Con el paso del tiempo, la Escuela de Verano fue creciendo en importancia y reconocimiento. Sus cursos comenzaron atener mayor profundi dad y fueron aceptados como créditos universitarios en distintas instituciones; el 
Centro y su cuerpo académico iban obteniendo reconocimiento nacional e internacional.

El crecimiento de la comunidad hispanohablante en Estados Unidos generó, hacia los años cuarenta del siglo pasado, una demanda de servicios educativos y vinculación con nuestro país que fue acogi da por la UNAM. Como resultado de esto, en 1944 comenzaron a ofrecerse, en San Antonio, Texas, cursos de español en lo que más adelante sería la Escuela Permanente de Extensión en San Antonio (EPESA) primera escuela de extensión de la Universidad.

Hoy en día, la EPESA simboliza una tradición de colaboración cultural y académica entre México y Estados Unidos. Gracias a su labor es posible promover un mejor entendimiento entre ambas naciones, así como la colaboración académica de la UNAM con instituciones de educación superior estadounidenses.

LAUNAM y el CEPE, siguiendo la tradición de enfrentar nuevos retos, crearon en 1995 la Escuela de Extensión en Canadá (ESECA), institución que constituyó el tercer punto de un triángulo de relaciones universitarias entre los países que integran la denominada región de América del Norte, en el contexto del inicio del Tratado de Libre Comercio en esta región. La ESECA realiza, desde entonces, funciones de gran rel evancia. Su trabajo ha sido reconocido por distintos actores académicos, culturales y sociales de Canadá.

En la actualidad, se han desarrollado escuelas de extensión en dos importantes espacios de concentración poblacional de origen mexicano: Chicago y Los Ángeles. Con éstas se busca dar apoyo a nuestros compatriotas en aquellas ciudades. Es importante mencionar que la respuesta de la sociedad y las distintas autoridades de los sectores público y privado así como de instituciones académicas y culturales de ambos países a estos proyectos ha sido extraordinaria.

En las escuelas de extensión (en nuestro país existen también dos escuelas de extensión fuera del campus universitario: CEPE-Taxco, en el estado de Guerrero y CEM Polanco, en la zona norte de la ciudad de México) se ofrece una amplia gama de cursos y servicios académi cos: cursos de formación de profesores de español, exámenes 
Para consultar la gama de servicios que se ofrecen en nuestras Escuelas, se puede acceder a la página de cada una de ellas a través del portal de Internet del CEPE. <http:// www.cepe. unam.mx.> de certificación de dominio de la lengua española, diplomados de arte, historia y literatura de México, así como diversas actividades cultural es y de vinculación con la comunidad. ${ }^{7}$

Resulta halagador observar cómo, lo que al gún día fue una Escuela de Verano para 67 al umnos, se ha convertido en un importante centro de enseñanza y difusión de nuestra lengua y cultura con siete sedes en tres países y más de 7000 al umnos al año. El futuro de esta aventura, estamos seguros, seguirá siendo ejemplar y de gran importancia para nuestra Universidad y para nuestro país.

\section{PROYECTOS ESTRUCTURALESDEL CEPE}

Para ejercer una política eficaz de difusión de la lengua española, ha sido necesario, entre otros programas, articular cuatro ejes estratégicos:

1. Plan de estudios de español como lengua extranjera (incluyendo asignaturas y diplomados de cultura).

2. Certificación del dominio de la lengua española.

3. Formación de profesores de español como lengua extranjera.

4. Programas de educación media en español, a distancia, para hispanohablantes que residen en países donde se habla otra lengua.

Desde nuestra perspectiva, sólo la articulación coherente de todos estos elementos asegura el éxito de un programa de difusión de la lengua dentro y fuera de los países en los que se habla. Con este enfoque, el CEPE ha trabajado intensamente en los últimos ocho años para concretar y armonizar su labor como entidad encargada de la difusión de la lengua y la cultura de México hacia el extranjero. A continuación desglosaremos de manera sintética el trabajo de nuestro Centro en cada uno de estos puntos. 
El Nuevo Plan de Estudios (NPE) del CEPE es el descenlace de un proceso de reflexión sobre los resultados del trabajo que se ha dado en este Centro desde su creación y del análisis de variables como el perfil de los alumnos extranjeros que han estudiado español en la UNAM dentro y fuera del país y los cambios históricos tanto en la concepción de la lengua como en los enfoques metodológicos para la enseñanza de la misma. Esta reflexión encuentra su justificación en los cambios sociales de los últimos decenios, en las nuevas necesidades provenientes del mundo del trabajo y de la economía para adaptar la formación de los adultos a las exigencias progresivas del ámbito social y profesional.

La base teórica del NPE tiene como eje la consideración la lengua como sistema y como instrumento de comunicación social. Este concepto dual ista de lengua coloca, por un lado, el complejo conjunto de reglas fonológicas, morfosintácticas y semánticas que constituye el dominio de la gramática, y por el otro la lengua como instrumento de comunicación social, objeto de estudio de la pragmática, la disciplina que toma en consideración los factores extral ingüísticosque determinan el uso de la lengua.

Este concepto de lengua se articula con un concepto de la enseñanza-aprendizajequeimplica la adquisición de una competencia comunicativa por parte del aprendiente. Esta competencia comunicativa se desglosa, para su mejor desarrollo, en cuatro competencias principales:

1. Gramatical, que se refiere al conocimiento del código lingüístico.

2. Sociolingüística, que hace referencia al conocimiento de las reglas que rigen la conversación en una cultura determinada.

3. Discursiva, relacionadacon el modo de combinar formas gramaticales y significados para dar cohesión y coherencia a un texto hablado o escrito.

4. Estratégica, que implica la capacidad para interactuar con los participantes de la conversación, para negociar significados. El currículo del NPE de español del CEPE fue planificado para armonizar 
el desarrollo de estas cuatro competencias, desde el planteamiento de sus objetivos y contenidos, hasta la evaluación de los resultados de aprendizaje.

En cuanto a las bases metodológicas, el planteamiento di dáctico del NPE parte de dos fundamentos del enfoque comunicativo: la enseñanza centrada en el alumno y la enseñanza centrada en el proceso. Ambos tienen repercusiones en la metodología de enseñanza, tanto en las decisiones previas a la programación como en la introducción de una perspectiva intercultural, en la que se asume que aprender una lengua para incorporarse a una nueva comunidad hablante supone una expansión de la propia personal idad social.

La aparición del documento Marco Común de Referencia Europeo para la enseñanza, apendizaje y evaluación de las lenguas (MERC), implicó una nueva revisión de contenidos del NPE que permitiera homologar los niveles mencionados con los planteados en el Marco. Esta revisi ón enriqueció el currículo a la vez que permitió establecer una homologación de niveles de acuerdo al siguiente cuadro:

\begin{tabular}{|c|c|}
\hline Niveles del NPE & Niveles del Marco \\
\hline $1-3$ & A1y A2 \\
\hline 47 & B1y B2 \\
\hline 8 & C1y C2 \\
\hline
\end{tabular}

Correspondencia de los niveles del NPE del CEPE con los niveles del Marco Común de Referencia Europeo.

Consideramos que esta homologación constituye una estrategia indispensable para el reconocimiento del NPE del CEPE a nivel internacional así como para el establecimiento de políticas de revalidación de estudios que faciliten la movilidad estudiantil a nivel mundial.

El diseño curricular emanado tanto del análisis del perfil del estudiante como del establecimiento del concepto de lengua y el enfoque metodológico mencionados, crista- 
liza en el diseño de una nueva serie de libros de texto para enseñar español como lengua extranjera. Se trata de ocho libros, fruto del escrupul oso trabajo de especialistas del CEPE que han dedicado sus esfuerzos en los últimos tres años a la realización de este proyecto.

Con la nueva serie de libros, - pilar fundamental de nuestro NPE-, contribuimos a la investigación aplicada a la docencia, al fomento editorial en español y a la difusión y distribución de una herramienta fundamental para estudiantes y profesores de español como lengua extranjera, en colaboración con empresas editoriales de al to prestigio mundial. Actualmente, la serie de libros se encuentra en proceso de edición.

EI NPE involucra también instrumentos de evaluación y certificación de la lengua vinculados estrechamente con el currículo. Así, desdehace un par de años existen los Certificados de Español como Lengua Adicional (CELA) en tres niveles: inicial, intermedio y superior. Los contenidos lingüísticos y temáticos del programa del CEPE que acabamos de mencionar, constituyeron el fundamento teórico y pedagógico para la elaboración de los exámenes que denominamos CELA en tres niveles: inicial, intermedio y superior, niveles equival entes a los del Diploma de Español como Lengua Extranjera (DELE), elaborados por la Universi dad de Salamanca y administrados por el Instituto Cervantes (IC). ${ }^{8}$

El cuadro que aparece a continuación muestra la estructura curricular del NPE del CEPE. Se trata de un esquema, en el cual las asignaturas de español se complementan con asignaturas de historia, arte y literatura de acuerdo con el nivel de dominio de la lengua. Conforme este nivel avanza, aumenta la carga académica de las asignaturas complementarias de cultura y disminuye la de español, por consi derar que el estudiante está cada vez más apto para estudiar, comprender y anal izar temas de la cultura de nuestro país en español.
Para acceder a información acerca del enfoque, metodología, diseño y contenido de los CELA, puede consultarse el artículo: Campos, Eva, "Certificado de Español como Lengua Adicional" ( CELA). Nivel Intermedio, en Decires Revista del Centro de Enseñanza para Extranjeros, núm 7. México, UNA M, 2005. 


\begin{tabular}{|c|c|c|c|c|}
\hline Nivel & $\begin{array}{c}\text { Horas de } \\
\text { español }\end{array}$ & $\begin{array}{c}\text { Horas complementarias de } \\
\text { cultura }\end{array}$ & $\begin{array}{c}\text { Total } \\
\text { horas }\end{array}$ & $\begin{array}{c}\text { Total } \\
\text { créditos }\end{array}$ \\
\hline Básico 1 & 90 & 18 & 108 & 7 \\
\hline Básico 2 & 90 & 18 & 108 & 7 \\
\hline Básico 3 & 90 & 18 & 108 & 7 \\
\hline Básico 4 & 90 & 18 & 108 & 7 \\
\hline Intermedio 1 & 78 & 30 & 108 & 7 \\
\hline Intermedio 2 & 78 & 30 & 108 & 7 \\
\hline Intermedio 3 & 78 & 30 & 108 & 7 \\
\hline Superior & 60 & 48 & 108 & 7 \\
\hline
\end{tabular}

Estructura académica del NPE de Español y Cultura.

En el cuadro siguiente se muestra una breve descripción que se da a los al umnos del programa de cada uno de los niveles que conforman el NPE. Al término de cada bloque, los alumnos están capacitados para presentar los exámenes de dominio CELA, en sus niveles inicial, intermedio y superior, respectivamente.

Nivel 1

Descripción

En este nivel conocerás formas de saludar, presentarte, agradecer y disculparte. Aprenderás a pedir y dar información personal, sobre otras personas, y sobre objetos

Básicol y lugares, en un contexto de la vida diaria. Estudiarás los verbos principales del español en presente, al gunos verbos muy usuales en pretérito y la perífrasis de futuro. Estudiarás el alfabeto, los números y expresiones relacionadas con el tiempo, los artículos, adjetivos, adverbios, pronombres y preposiciones más usuales.

En este nivel aprenderás a participar en intercambios sociales como: felicitar, concertar una cita, invitar, sugerir, aceptar o rechazar ofrecimientos, expresar acuerdo y des-

Básico2 acuerdo, conocimiento y desconocimiento, pedir permiso, pedir ayuda, pedir y dar información sobre eventos y expresar opiniones y juicios. Estudiarás las sílabas y diptongos, reglas de acentuación, verbos regulares e irregulares más frecuentes en pretérito y copretérito y el futuro simple. Conocerás más adverbios y frases adverbiales, el objeto directo e indirecto con sus pronombres complementarios, las palabras de enlace básicas y más preposiciones.

Básico 3

En este nivel aprenderás a narrar acciones diversas en el pasado, a comunicarte con cortesía, a expresar matices de una acción o estado, a señalar finalidad, objetivo, propósito e intención, relaciones de cantidad y a comparar. Estudiarás los signos de puntuación, las distintas irregularidades verbales y al gunas perífrasis verbales usuales. Profundizarás en el uso de pronombres de objeto directo e indirecto.

En este nivel estudiarás la forma de narrar acciones durativas y aprenderás a describir, caracterizar, individualizar o ubicar una entidad, la formación de adverbios, de

Básico4 aumentativos, diminutivos y despectivos, oraciones exclamativas y exhortativas y repasarás el uso de pretérito y copretérito. Conocerás las oraciones condicionales, el modo imperativo y el presente de subjuntivo con verbos de opinión, voluntad, entendimiento y percepción sensible. 


\begin{tabular}{|c|c|c|c|}
\hline Nivel & \multicolumn{3}{|c|}{ Descripción } \\
\hline & \multicolumn{3}{|c|}{ CELA INICIAL } \\
\hline Intermedio1 & \multicolumn{3}{|c|}{$\begin{array}{l}\text { En este nivel aprenderás a expresar duda y negación, a caracterizar sujetos y ob- } \\
\text { jetos, lugares, momentos y maneras, a expresar condición real, irreal o hipotéti- } \\
\text { ca y a formular conjeturas y suposiciones sobre situaciones. } \\
\text { Estudiarás la formación y uso de los tiempos antecopretérito y pretérito de sub- } \\
\text { juntivo, así como el antefuturo y pospretérito con valor de conjetura, los verbos } \\
\text { de lengua y el estilo indirecto. Conocerás la construcción de oraciones interroga- } \\
\text { tivas, enfáticas y adjetivas, más perífrasis verbales, adverbios y frases } \\
\text { adverbiales, pronombres, preposiciones y frases prepositivas. }\end{array}$} \\
\hline Intermedio2 & \multicolumn{3}{|c|}{$\begin{array}{l}\text { En este nivel aprenderás a reclamar y protestar, a dar ánimos y tranquilizar, dar } \\
\text { y pedir recomendaciones, expresar acciones realizadas sin intención, expresar } \\
\text { cambios de estado emotivo, psíquico y físico, expresar la manera real o figurada } \\
\text { en la que se realiza una acción, usar registros formales e informal es adecuados } \\
\text { a situaciones con diferentes interlocutores. Conocerás diferentes formas de ex- } \\
\text { presar impersonalidad. Estudiarás el antepresente y antepretérito de subjunti- } \\
\text { vo, el antepospretérito de indicativo, distintas conjunciones temporales, Ias ora- } \\
\text { ciones subordinadas de lugar, tiempo y modo, las oraciones finales y causales, } \\
\text { las oraciones subordinadas concesivas. Conocerás más perífrasis, frases } \\
\text { adverbiales y prepositivas y nexos discursivos muy usuales. }\end{array}$} \\
\hline Intermedio3 & \multicolumn{3}{|c|}{$\begin{array}{l}\text { En este nivel analizarás diferentes tipos de discurso, tanto oral es como escri- } \\
\text { tos, conocerás los rasgos de distintas variantes dialectales del español y estu- } \\
\text { diarás el uso de más marcadores discursivos. I dentificarás distintos registros } \\
\text { sociales y conocerás palabras y frases de connotación cultural. }\end{array}$} \\
\hline & \multicolumn{3}{|c|}{ CELA INTERMEDIO } \\
\hline Superior & \multicolumn{3}{|c|}{$\begin{array}{l}\text { En este nivel conocerás varios tipos de nexos discursivos y las formas de organizar un tex- } \\
\text { to. Aprenderás a reformular ideas en distintas formas lingüísticas para dar énfasis, dife- } \\
\text { renciar según la situación o el interlocutor y eliminar la ambigüedad. Conocerás expresio- } \\
\text { nes coloquial es de la variante mexicana del español. Estudiarás construcciones enfáticas } \\
\text { con el verbo ser, usos del gerundio y oraciones subordinadas adnominales. Repasarás y } \\
\text { profundizarás en el uso de indicativo y subjuntivo en diferentes tipos de subordinación } \\
\text { oracional y repasarás el discurso indirecto. }\end{array}$} \\
\hline & \multicolumn{3}{|c|}{ CELA SUPERIOR } \\
\hline \multicolumn{4}{|c|}{$\begin{array}{l}\text { Descripción de los cursos de español del } \\
\text { diplomados de cultura que comple- } \\
\text { studios de español son los siguientes: }\end{array}$} \\
\hline $\begin{array}{l}\text { Nivel de } \\
\text { español }\end{array}$ & Historia & Arte & Literatura \\
\hline Básico 1 & & $\begin{array}{l}\text { - Taller de baile de } \\
\text { salón: Salsa }\end{array}$ & \\
\hline Básico 2 & & - Expresión corporal & - Cancionero mexicano \\
\hline Básico 3 & $\begin{array}{l}\text { - Geografía Gene- } \\
\text { ral de México }\end{array}$ & - Expresión corporal & $\begin{array}{l}\text { - Cultura mexicana } \\
\text { en } 10 \text { crónicas }\end{array}$ \\
\hline Básico 4 & $\begin{array}{l}\text { - Historia General } \\
\text { de México }\end{array}$ & $\begin{array}{l}\text { - Cortometrajes y docu- } \\
\text { mentales mexicanos }\end{array}$ & \\
\hline
\end{tabular}




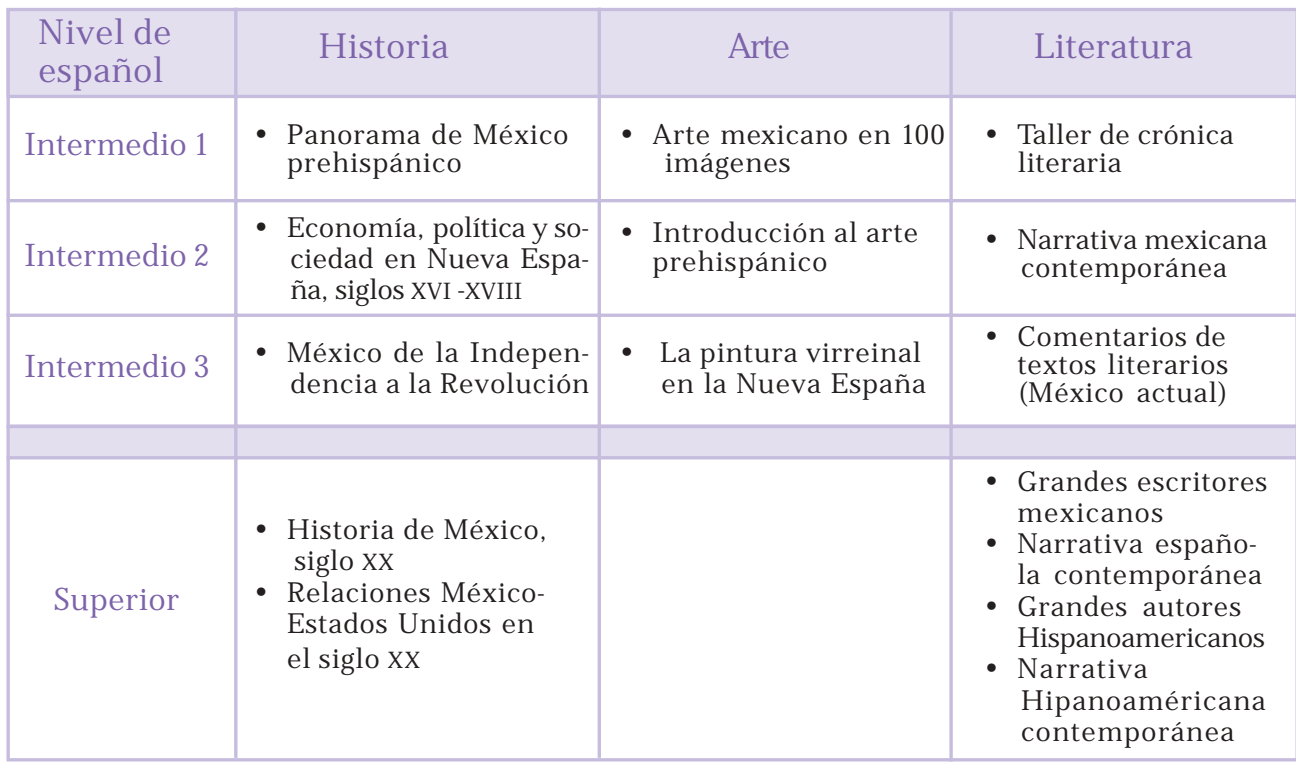

Asignaturas complementarias de Cultura del NPE del CEPE.

Diplomado

Diplomado en
Estudios Mexicanos

La Vida Cotidiana a través del Arte

Un Recorrido por laHistoria de México

Grandes Figuras de la Literatura Hispanoamericana
Objetivo

Ofrecer una perspectiva multidisciplinaria, que proporcione al alumno las categorías analíticas para una interpretación de la historia, el arte y la literatura mexicanos. Está diseñado a partir de núcleos temáticos que permiten una comprensión integral y simultánea de los momentos históricos, las expresiones artísticas y las transformaciones ideológicas ocurridas en el pasado mexicano.

A partir del estudio del arte, fomentar en el alumno una mayor comprensión de la personalidad y cultura del mexicano. Los alumnos nacionales, asimismo, reconocerán a través de la obra artística, usos, costumbres y tradiciones cuyo estudio sin duda dará pie a una reinterpretación de su propia idiosincrasia.

Proporcionar al alumno las consideraciones hipotéticas y la información fáctica relativa a la realidad política, económica y social de la historia mexicana, con el fin de que adquiera herramientas conceptuales de análisis para comprender e interpretar el acontecer histórico de México.

Delimitar por géneros literarios el legado de las letras hispanoamericanas; identificar a aquellos grandes narradores, poetas y ensayistas de nuestra región que han conformado una concepción artística propia. Asimismo, reconocer las principal es épocas, corrientes y generaciones literarias así como renovar los enfoques de la historia literaria y de la metodología del análisis literario.
Duración

225 horas

120 horas

120 horas

120 horas 


\section{CeRTIFICACIÓN}

La certificación del dominio de la lengua española es un tema que ha preocupado especial mente a la UNAM en años recientes. Creemos que es necesario hacer esfuerzos conjuntos entre países para lograr una regulación de la calidad y el establecimiento de las equivalencias necesarias para la creación y el mutuo reconocimiento de los instrumentos de certificación de nuestras instituciones. En este sentido, el CEPE, que ha elaborado sus propios instrumentos de evaluación como el CELA -y antes de estos un Examen de Posesión de la Lengua Española (EPLE) - , ha trabajado en los últimos años con el IC, para la creación del Sistema Internacional de Certificación del Español como Lengua Extranjera (SICELE), en un acuerdo firmado por rectores universitarios, autoridades educativas y representantes de instituciones públicas y privadas de 20 países hispanohablantes en octubre de 2005. El objetivo principal de este proyecto es que el español cuente, por primera vez, con titulaciones reconocidas por todos los países hispanohablantes.

Actualmente en Hispanoamérica se carece, desafortunadamente, deuna políticalingüística deal canceregional que permita orientar los procesos lingüísticos hacia objetivos definidos en común y que por tanto, regule -entreotros aspectos-la evaluación y certificación de la competencia lingüística del español. Esta situación propicia un panorama fragmentado caracterizado por la fal ta de criterios y estándares comunes, con la consecuente proliferación de exámenes y certificaciones de desigual calidad.

EI SICELE es un organismo cuyo objetivo es asegurar la calidad, transparencia y coherencia de los certificados a él adheridos, así como garantizar el cumplimiento de una serie de parámetros de cal idad en cuanto a los procedimientos de certificación del dominio de la lengua española, la correlación de niveles de competencia, la capacitación de los evaluadores, así como la corrección, calificación, validez y fiabilidad de las pruebas. ${ }^{9}$

La UNAM participa en Ias comisiones ejecutiva y académica del SICELE no sólo por su prestigio académico, sino porque ha colaborado estrechamente con el Ic en la concepción de esta organización. La UNAM y el IC identi-
2. Los exámenes y certificados son instrumentos de gran utilidad porque generan, regulan y orientan la actividad académica, constituyen un refuerzo para los estudiantes, contribuyen a su desarrollo personal como herramientas que facilitan la promoción académica y laboral, la inserción social y la integración, y son, sobre todo, exponentes de las garantías que instituciones y estados deben proveer en aras de la equidad y de la igualdad de oportunidades. Dada su importancia, el sector de la evaluación y de la certificación debe regirse inevitablemente por principios de calidad y eficacia y las tareas propias de esta actividad deben, a su vez, generar un impacto positivo en los procesos de enseñanza aprendizaje y en la sociedad en su conjunto. (Documento de trabajo de la Comisión académica del SICELE, 2006). 
ficaron la necesidad de impulsar una iniciativa de este tipo debido a un proyecto previo que han desarrollado conjuntamente desde 2004, el Certificado Internacional del Español (CIE), un sistema de evaluación que aspira a ser reconocido por el SICELE y a constituir un modelo para otros exámenes o sistemas de eval uación diseñados por otros países de habla hispana. Aunado a lo anterior, en 2004, la UNAM firmó con el IC un convenio para el desarroIlo del CIE, un servicio de evaluación orientado principalmente al mundo académico, ya que, además de la competencia lingüística, servirá para evaluar habilidades cognitivas cuyo dominio acreditaría un desempeño adecuado en el nivel universitario. Este examen vendrá a llenar un vacío importante, ya que no existeen la actualidad al go similar.

En el marco de este convenio, la UNAM tiene a su cargo el diseño científico del instrumento, mientras que el IC aporta la gestión y administración de las pruebas, así como los recursos materiales y humanos para la aplicación de los exámenes.

El trabajo conjunto del IC y de la UNAM en ambos proyectos ha sido motivado tanto por necesidad de impulsar el desarrol lo de la certificación de la lengua español a basada en acuerdos y en el respeto a la diversidad de las distintas variantes dialectales, como por el deseo de compartir con otros países hispanoamericanos los avances logrados y crear una red de intercambio de información que nos permita avanzar conjuntamente en esta importante tarea.

Con iniciativas como la creación del SICELE y del CIE, el IC y laUNAM aportan a la construcción de una respuesta al reto global de diseñar políticas nacional es y supranacionales destinadas a incrementar la presencia de la lengua española con productos educativos de calidad, contribuyendo de esta manera a la difusión y valoración de las distintas variedades del español y de los repertorios cultural es que la acompañan. 
No hay programa de estudios, por maravilloso que sea, que funcione sin la intervención experta de un profesor. Estees un punto fundamental en el desarrol lo de políticas de difusión de una lengua. No basta con tener estudios en literatura en lengua española o afines para enseñar una lengua; es necesario contar con bases teórico- metodológicas parala enseñanza de una lengua extranjera. Es por ello que las universidades de los países hispanohablantes debemos preocuparnos por atender esteeslabón en la cadena de estrategias para la difusión adecuada de nuestra lengua más al lá de nuestras fronteras.

El crecimiento en la demanda de la enseñanza del español como lengua extranjera ha provocado la petición reiterada del sector conformado por las escuelas de enseñanza de español de México y deinstituciones educativas del extranjero, principal mente de Brasil, Estados Unidos y Canadá, hacia la UNAM de formar cuadros profesionales, certificar los estudios que imparten y material es de enseñanza adecuados a su práctica docente.

Hace algunas décadas, el CEPE comenzó impartiendo cursos de verano de actual ización para profesores de español. La demanda de éstos y de más cursos profesionalizantes en el área, llevaron al CEPE a integrar un curso de Formación de Profesores de Español como Lengua Extranjera, de manera presencial. Este curso, al paso de los años se convirtió en un diplomado con una gran demanda por parte de profesional es que no contaban con una certificación para ejercer su actividad en nuestro país y en el extranjero.

Más adelante, hacia fines de los años noventa, el CEPE recibió apoyo de la Secretaría de Relaciones Exteriores para convertir el Diplomado de Formación de Profesores, en un programa en línea, debido a la al ta y creciente demanda que de éstos hay en Estados Unidos. A partir de 2002, el CEPE ofrece en línea el Diplomado de Formación de Profesores de Español como Lengua Extranjera (DFPELE), con una duración de un año, diez asignaturas y un total de 450 horas. A continuación se presentan los datos estadísticos sobre las primeras seis generaciones del DFPELE. 


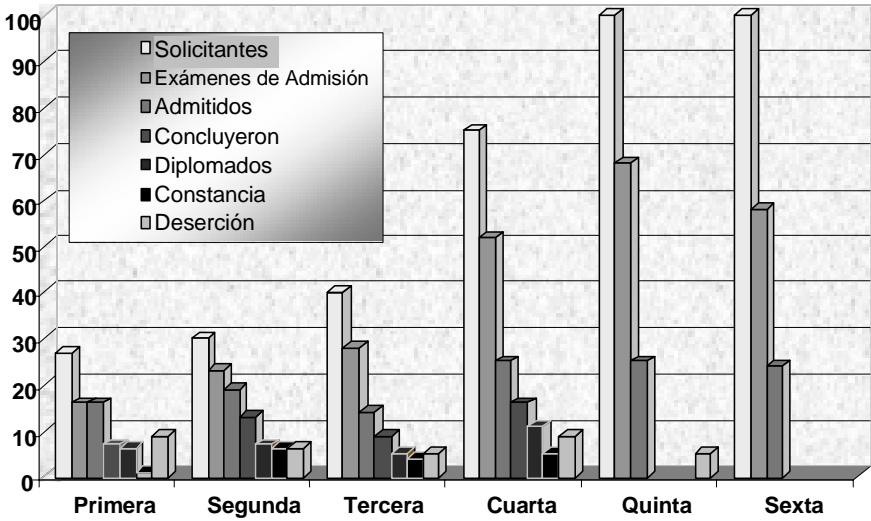

Estadísticas de ingreso y conclusión de estudios de las primeras seis generaciones del DFPELE.

Nacionalidades la a 6a generación DFPELE

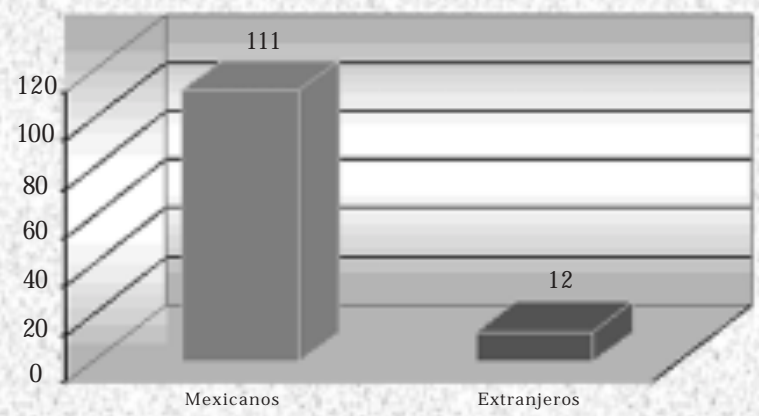

Relación de mexicanos y extranjeros que han participado en el DFPELE.

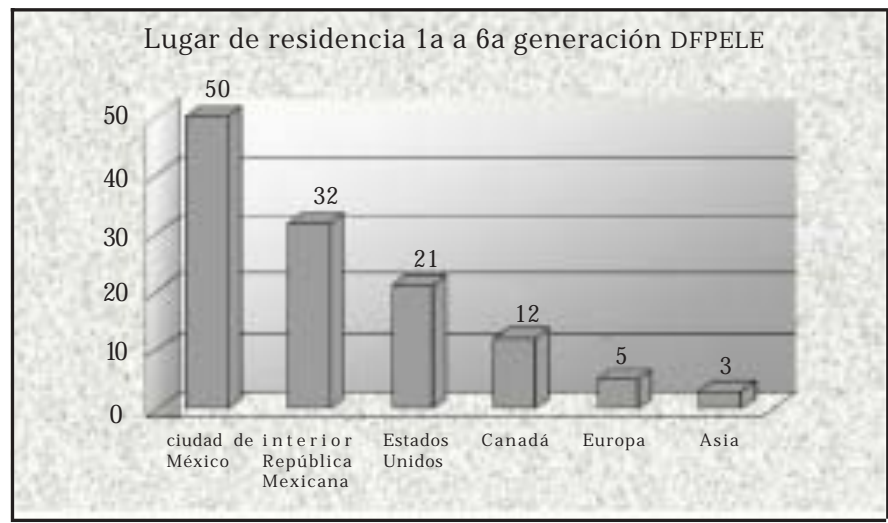

Relación de los lugares de residencia de los estudiantes del DFPELE. 
La exitosa experiencia de cinco generaciones egresadas del Diplomado en línea han conducido a que se trabaje en la integración de un programa más, el de Especialización en Enseñanza del Español. Se trata de un programa de posgrado, también en línea, dirigido a profesores en ejercicio que desean dar un paso más en su formación docente. Se trata de un programa de dos años, que integra más elementos teóricos y prácticos para la formación de docentes de lengua en 14 asignaturas y 488 horas de clase.

Los tres programas de Formación de Profesores de Español como Lengua Extranjera de la UNAM están articulados en dos ejes:

1. El eje del sistema de lengua, integrado por asignaturas relativas a los aspectos descriptivos y normativos de la lengua en todos sus niveles: fonológico, fonético, morfosintáctico, pragmático y discursivo.

2. El eje de enseñanza de una lengua extranjera, integrado por asignaturas relativas a la metodología de enseñanza de lenguas, teorías del aprendizaje de lenguas y nociones sobre su adquisición, metodología de la enseñanza de aspectos culturales en un contexto de interculturalidad, diseño de material es para la enseñanza de lenguas, uso delas nuevas tecnol ogías en el proceso deenseñanza-aprendizaje de lenguas y conceptos y criterios fundamentales de la evaluación del proceso de aprendizaje. A continuación se puede apreciar, de manera esquemática, la estructura del programa de especialización en enseñanza de español como lengua extranjera en línea. Los cuadros sombreados muestran cada una de las asignaturas que forman parte del programa; los cuadros blancos muestran los ejes que articulan el programa. 


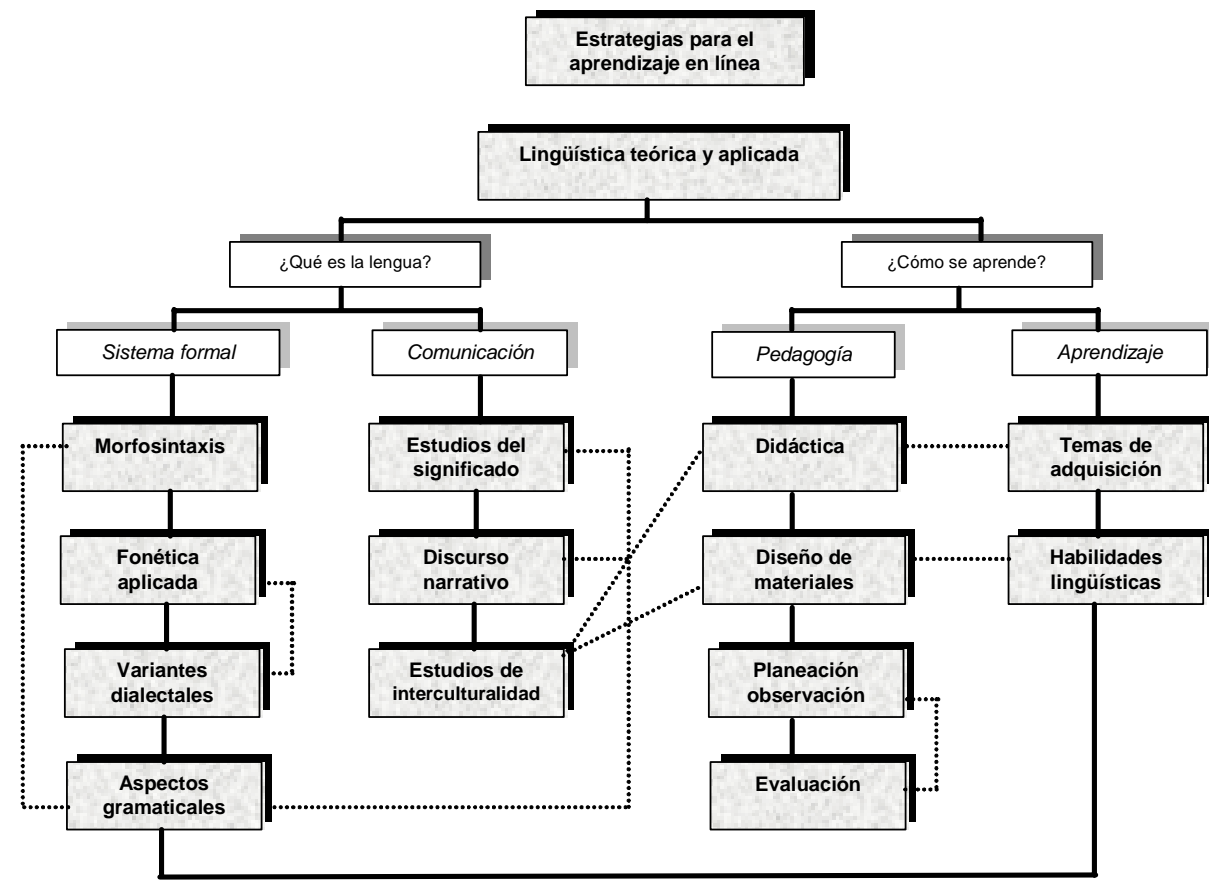

Estructura académica de la especialización en línea en Enseñanza del Español como Lengua Extranjera.

El objetivo de ofrecer en línea dos de estos tres programas responde, como es natural, a la necesi dad de atender la demanda de profesionalización de profesores en ejercicio para quienes desplazarse a un lugar para real izar sus estudios representaría un problema laboral. La educación a distancia que permite la tecnología actual facilita enormemente, no sólo la inscripción de más profesores a nuestros programas, sino también la creación de posgrados conjuntos con universidades extranjeras. En este momento, Ia UNAM trabaja con universidades de Estados Unidos y Canadá preocupadas por ofrecer alternativas profesionalizantes a los académi cos de español de esos países. Para ellos, la posibilidad de establecer convenios con la UNAM para integrar programas conjuntos representa un enriquecimiento sin precedentes de sus programas de formación docente en el área de la enseñanza de español como lengua extranjera. Sus estudiantes tendrán la posibilidad de interactuar con maestros hispanohablantes especial istas en la enseñanza del 
español así como con profesores en formación que enfrentan distintas real idades de enseñanza del idioma.

De esta misma forma creemos que otras universidades de países hispanohablantes deben unirse al esfuerzo de crear programas de formadores docentes a distanciay crear convenios de colaboración y reconocimiento de la val idez deestos programas. Prevemosqueesestaunainiciativa que rendirá grandes frutos para todas las partes involucradas y que impactará deuna manera muy positiva ala difusión de la lengua española a nivel internacional.

\section{B@UNAM}

La UNAM cuenta con una tradición de 139 años en el área de educación media superior. Su sistema presencial está integrado por dos subsistemas de bachillerato: el de la Escuela Nacional Preparatoria y el del Colegio de Ciencias y Humanidades. Más de 105 mil al umnos son atendidos por estos subsistemas en un total de 14 plantel es distribuidos en la ciudad de México y su zona metropolitana.

La capacidad, experiencia y los amplios recursos académicos de la UNAM han hecho posible la creación de un bachillerato a distancia: el B@UNAM. Se trata de un programa cuya finalidad es contribuir a la formación de los hispanohablantes en nuestro país y en el extranjero. EI programa fue creado por destacados profesionales del bachillerato presencial de la UNAM; se contó además con la asesoría de más de 70 investigadores y profesores de las distintas facultades de nuestra institución.

El B@UNAM está basado en un enfoque interdisciplinario centrado en el aprendizaje del alumno, con un acento decidido en el desarrollo de habilidades. Tiene una duración total de dos años, a los que se añaden de ocho a trece semanas de cursos propedéuticos y tutoriales que tienen como propósito asegurar que los aspirantes tengan un nivel necesario para abordar los contenidos del plan de estudios e incrementar sus probabilidades de éxito en las asignaturas del primer módulo, así como eliminar posibles dificultades en las mismas.

El plan de estudios se estructura en veinticuatro asignaturas que abordan de manera interdisciplinaria los 
10 Información tomada de $<$ http:// somi. cinstrum. unam. mx/virtualeduca2006/pdf/ 195-CV.pdf>. Se trata de Villatoro, Carmen; Díaz del Castillo, Isabel; Vadillo Guadalupe y Bazan, José.

BQUNAM: innovación en el bachillerato mexicano. México, U N A M Consejo Académico de Bachillerato, 2006. José Luis Barrios Lara, "El cuerpo doliente", en $\mathbb{E}$ cuerpo aludido, cat. de la exp., del mismo nombre, México, p. 163. contenidos (conocimientos y habilidades) tanto de carácter transversal como específico, con el propósito de promover el aprendizaje en un contexto cercano a la realidad, en la que las situaciones requieren la utilización de saberes interdisciplinarios integrados. Se procuró un equilibrio de los tiempos dedicados a H umanidades y Ciencias Social es, por un lado, y Ciencias Naturales, Matemáticas, por el otro. Las asignaturas están organizadas en cuatro unidades didácticas, lo que permite trabajar efectivamente el desarrollo de competencias en el al umno.

El planteamiento de las actividades asegura la adecuada dosificación de conocimientos y la construcción progresiva de conceptos. Cada una de las asignaturas se cursa en periodos de cuatro semanas con un tiempo de dedicación de 20 horas a la semana por parte del alumno. ${ }^{10}$

Al ofrecer el B@UNAM, la Universidad busca lograr una mayor equidad educativa y que los hispanohablantes



Mapa curricular del B@UNAM 
puedan obtener las herramientas y las habilidades necesarias para mejorar sus condiciones de vida. Asimismo, se persigue incrementar las posibilidades de nuestros estudiantes para que tengan acceso a la educación superior en los países de América del Norte o bien su ingreso a las universidades de su país de origen. Si consideramos el hecho de que la población de origen mexicano en Estados Unidos es de 20 millones y que el 43 por ciento no cuenta con educación media superior (High School), podemos vislumbrar la magnitud y el futuro de un programa comoel B@UNAM.

Cabe destacar que, al tratarse de un programa enteramente en español, que incluye también la asignatura de inglés como segunda lengua, da la posibilidad a los estudiantes de, por una parte, conservar su derecho a pensar y estudiar en su idiomay, por otra, insertarse en el sistema educativo norteamericano. En este sentido, Ia UNAM está haciendo esfuerzos importantes de vinculación con países como Estados Unidos y Canadá para lograr una doble acreditación del programa. Se trata de una respuesta más de nuestra Máxima Casa de Estudios para difundir el conocimiento en nuestra lengua entre los hispanohablantes que viven en aquel los países y que demandan la posibilidad de avanzar en su formación en español con un reconocimiento oficial conjunto entre un país hispanohablante y el país en el que viven.

Hoy en díaB@UNAM es una realidad. Está iniciando la primera generación de estudiantes de este programa en nuestras escuelas deextensión en Estados Unidos y Canadá y el panorama para el futuro es al entador. Estamos convencidos de que la tendencia de las comunidades de origen latino-hispano en esos países está orientada hacia una mayor integración ala sociedad, no haciala separación. Dicha afirmación supone que las influencias de esta comunidad estarán, cada vez más, determinadas por su mayor participación en las diversas esferas de la sociedad. Desde esta perspectiva, el programa que acabamos de esbozar adquiere una gran relevancia al contribuir a la difusión del conocimiento en español, a la conclusión de estudios de bachillerato de los hispanohablantes y su consecuente acceso a la educación superior y a mejores condiciones de trabajo. 


\section{CONCLUSIONES}

En este trabajo hemos querido mostrar la labor y la experiencia que ha acumulado Ia UNAM en materia de difusión de la lengua española. Hasta este momento, las políticas de estado concernientes a la difusión de la lengua se han concretado a las acciones realizadas por ella, que ha desarrollado, entre otras, las estrategias académicas mencionadas: creación de planes de estudio, instrumentos de certificación de la lengua, programas de formación de profesores presenciales y a distancia y programas de educación media superior en español.

Creemos, sin embargo, que esto no es suficiente. Debemos reconocer que hoy en día los esfuerzos de los países de Hispanoamérica están concentrados hacia el interior de los países y poca atención se ha dado a políticas exteriores de difusión del conocimiento en español . Los programas esbozados son sólo un ejemplo de lo que puede hacerse en este campo, pero hay muchas más acciones que pueden y deben realizarse en este sentido.

Pensemosque, en treintaaños más, lainfluencia hispana en el mundo será más notoria en todos los sectores y que la población hispanohablante en el mundo empujará la promoción de nexos académicos, económicos y culturales entre sus países de origen y sus países de residencia, todo esto propiciado por la creciente conformación de sociedades transnacionales donde las comunicaciones permiten un gran acercamiento entre habitantes de países geográficamente distantes.

El crecimi ento de nuestra lengua demanda la intervención de organismos públicos y privados así como de instituciones académicas y culturales, para que se sumen a esfuerzos conjuntos de los países, especialmente los de América Latina, para seguir ofreciendo respuestas creativas, eficaces y de alto nivel a las necesidades de expansión de nuestra lengua. 